\title{
Concentração de nitrato no perfil do solo fertigado com diferentes concentrações de fontes nitrogenadas
}

\author{
Eugênio F. Coelho ${ }^{1}$, Flávio da S. Costa ${ }^{2}$, Ana C. P. da Silva ${ }^{3} \&$ Gian C. Carvalho ${ }^{4}$
}

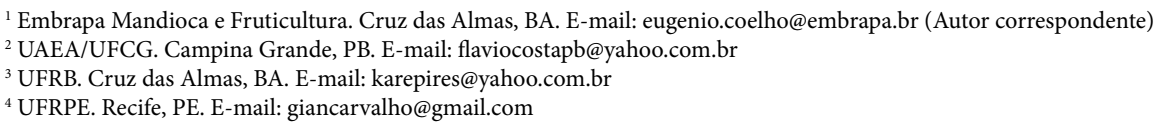

Palavras-chave:

solução do solo extrato de saturação ureia nitrato de potássio

\begin{abstract}
R E S U M O
Objetivou-se, neste trabalho, avaliar o efeito da concentração de nitrato de potássio e ureia da água de irrigação no teor de nitrato da solução do solo e do extrato de saturação, em duas profundidades do sistema radicular da bananeira tipo Plátano, cultivar Terra Maranhão fertigada. O experimento conduzido entre janeiro e dezembro de 2008 seguiu um delineamento em blocos casualizados com três repetições em esquema fatorial 2 x 4, em que os tratamentos consistiram no uso de duas fontes de nitrogênio (ureia e nitrato de potássio) sob quatro concentrações $\left(2,7 ; 4,0 ; 6,5\right.$ e 7,2 $\left.\mathrm{g} \mathrm{L}^{-1}\right)$, aplicadas via gotejamento, com três emissores de $4 \mathrm{~L} \mathrm{~h}^{-1}$ por planta. Amostras de solo e de solução do solo foram colhidas mensalmente em todos os tratamentos nas profundidades de 0,30 e $0,60 \mathrm{~m}$, com determinação em laboratório da concentração de nitrato na solução do solo e no extrato de saturação. Os resultados permitiram concluir que o aumento da concentração do fertilizante nitrogenado da água na fertigação implicou em aumento da concentração do íon nitrato na solução do solo e no extrato de saturação para as duas fontes de nitrogênio aplicadas.
\end{abstract}

Key words:

soil solution

saturation extract

urea

potassium nitrate

\section{Concentration of nitrate in the soil profile fertigated with different concentrations of nitrogen sources}

\begin{abstract}
A B S T R A C T
The objective of this study was to evaluate the effects of concentration of urea and potassium nitrate in the irrigation water on the concentration of nitrate in the soil solution and in saturation extract of soil at two depths of root system of Plaintans banana cv Terra Maranhão under fertigation. The experiment was carried out during the period of January to December, 2008 and followed a randomized block design with three replications in a $2 \times 4$ factorial scheme where treatments consisted of the use of two nitrogen sources (urea and potassium nitrate) under four concentrations $\left(2.7 ; 4.0 ; 6.5\right.$ and $\left.7.2 \mathrm{~g} \mathrm{~L}^{-1}\right)$, applied by drip irrigation with three $4 \mathrm{~L} \mathrm{~h}^{-1}$ emitter per plant. Soil and soil solution samples were collected monthly in all treatments at depths of 0.30 and $0.60 \mathrm{~m}$ and nitrate concentration was determined in the soil solution and saturation extract. Results allowed to conclude that the increase of nitrogen fertilizer concentration in fertigation water caused an increase of nitrate ion concentration in the soil solution and in saturation extract for the two applied sources.
\end{abstract}

\section{INTRODUÇÃo}

A bananeira apresenta crescimento lento até o quarto mês, com pequena absorção de nutrientes e demanda por água. No entanto, do quarto mês até o florescimento o crescimento é rápido e necessita de maiores quantidades de água e nutrientes para seu bom desenvolvimento e produção de frutos. A nutrição mineral aplicada em níveis compatíveis com as exigências da planta aumenta a produtividade e a qualidade dos frutos (Silva \& Borges, 2008). Para a incorporação de nutrientes ao solo a utilização de sistema de fertigação vem sendo amplamente utilizada devido à economia de mão-de- obra, flexibilidade de aplicação e eficiência do seu uso (Santana et al., 2007; Teixeira et al., 2011).
A avaliação da fertigação requer conhecimento da condição iônica do solo, acompanhamento da aplicação dos fertilizantes, observação da concentração dos mesmos na solução de injeção bem como na saída dos emissores, a uniformidade de distribuição ao longo da área e o acompanhamento da distribuição dos nutrientes ao longo do perfil do solo. A avaliação da condição iônica pode ser realizada através de amostragens da solução do solo por meio de extratores de solução (Souza et al., 2005) e do extrato de saturação que é coletado de amostras de solo.

$\mathrm{O}$ uso de fontes nitrogenadas em fertigação acelera a dinâmica do nitrogênio no solo resultando no aumento da concentração de nitrato na solução do solo que, por ser de alta mobilidade, pode ser lixiviado para os lençois freáticos. A 
presença do nitrato na solução do solo depende dos atributos químicos do solo, da fonte de nitrogênio, da massa aplicada e da concentração do fertilizante nitrogenado na água de irrigação. Segundo Andrade et al. (2009), a lixiviação do nitrato é potencializada pelas propriedades físicas dos solos, pelas práticas agrícolas intensivas e pela elevada dotação de água empregada na irrigação.

O manejo da fertigação, que procura aplicar o fertilizante no momento e na quantidade adequada, requer o conhecimento do comportamento do nitrato no perfil do solo sob fertigação para diferentes fontes nitrogenadas de forma a ser possível elaborar critérios para uso dessas fontes. Da mesma forma, a concentração da solução de injeção na água de irrigação pode influenciar na concentração de nitrato na solução do solo e no extrato de saturação, sendo necessário conhecer os efeitos da concentração dos fertilizantes da água de irrigação na concentração do nitrato no perfil do solo. De acordo com Donagemma et al. (2008) a aplicação de dosagens de nitrogênio na solução injetora em fertigações deve ser cuidadosa para evitar perdas de nitrogênio por lixiviação em razão da mobilidade diferencial desse nutriente, no sentido de prevenir a contaminação de água subterrânea por nitrato.

Torna-se necessário avalia, para diferentes fontes nitrogenadas, em particular, amídicas e nítricas, o efeito da concentração dos fertilizantes na água de irrigação na concentração do íon nitrato no perfil do solo a curto e durante o ciclo das culturas cultivadas.

Objetivou-se, neste trabalho, avaliar o efeito da concentração de nitrato de potássio e ureia da água de irrigação na concentração de nitrato da solução do solo e do extrato de saturação para duas profundidades do sistema radicular da bananeira tipo Plátano fertigada.

\section{Material e Métodos}

O trabalho foi desenvolvido na área experimental da Embrapa Mandioca e Fruticultura, entre janeiro e dezembro de 2008, localizada no município de Cruz das Almas-BA (latitude $12^{\circ} 48^{\prime} \mathrm{S}$; longitude $39^{\circ} 06^{\prime} \mathrm{W}$; altitude $225 \mathrm{~m}$ ). O clima da região é classificado como úmido a subúmido, com pluviosidade média anual de $1.143 \mathrm{~mm}$. A cultivar bananeira Terra Maranhão foi plantada no espaçamento 2,0 x 2,5 m; o solo da área experimental é classificado como Latossolo Amarelo com textura franca; com $444 \mathrm{~g} \mathrm{~kg}^{-1}$ de areia total, $131 \mathrm{~g} \mathrm{~kg}^{-1} \mathrm{de}$ silte, $425 \mathrm{~g} \mathrm{~kg}^{-1}$ de argila, densidade de $1,55 \mathrm{~kg} \mathrm{dm}^{-3}$, umidade correspondente à capacidade de campo e ao ponto de murcha permanente de $0,23 \mathrm{e} 0,16 \mathrm{~m}^{3} \mathrm{~m}^{-3}$, respectivamente. Os atributos químicos do solo por ocasião do início do experimento são apresentados na Tabela 1.
O experimento seguiu um delineamento em blocos casualizados com três repetições em esquema fatorial $2 \times 4$, cujos tratamentos consistiram no uso de duas fontes de nitrogênio (ureia e nitrato de potássio) sob quatro concentrações (2,7; 4,0; 6,5 e 7,2 $\mathrm{g} \mathrm{L}^{-1}$ ), aplicadas via gotejamento com três emissores de $4,0 \mathrm{~L} \mathrm{~h}^{-1}$ por planta; os níveis de nitrogênio seguiram a recomendação de Borges et al. (2002). A lâmina de água aplicada por evento de irrigação foi baseada na reposição da evapotranspiração da cultura (ETc), determinada pela evapotranspiração máxima de referência, coeficientes de cultura e coeficientes de localização (Coelho et al., 2006; Coelho et al., 2012). A distribuição dos tratamentos foi feita por meio de registros e linhas de derivação a partir de um cabeçal de controle no início da área. A fertigação foi realizada usando-se uma bomba injetora de acionamento hidráulico com uso de diafragma; a concentração da água de irrigação foi monitorada a cada fertigação com amostragem da água na saída do emissor e no recipiente da solução de injeção.

Amostras de solução do solo foram colhidas mensalmente por meio de extratores de solução em todos os tratamentos nas profundidades de 0,30 e 0,60 m, isto é, na zona radicular de maior atividade e na borda inferior do sistema radicular da planta. Nas mesmas profundidades e na mesma frequência foram retiradas amostras de solo para avaliação do extrato de saturação. As amostras de solo foram enviadas ao Laboratório de Irrigação e Fertigação da Embrapa Mandioca e Fruticultura onde foram secadas em estufas e processadas para obtenção do extrato de saturação (EMBRAPA, 1997). Extratores de solução do solo foram instalados a $0,20 \mathrm{~m}$ do pseudocaule nas profundidades 0,30 e $0,60 \mathrm{~m}$ em cada parcela experimental entre o pseudocaule e o gotejador; a coleta de amostras de solução do solo foi feita após um tempo de duas horas da aplicação do vácuo $(-70 \mathrm{kPa})$ nos extratores com uma bomba de vácuo manual. A amostragem para extrato de saturação foi feita simultaneamente à da solução do solo com uso de trado holandês numa frequência mensal.

As soluções resultantes foram processadas obtendo-se a concentração de nitrato com uso de um kit específico de determinação rápida (Card Horiba) para estimativa do íon nitrato. O kit foi inicialmente calibrado com uso de soluções de concentrações conhecidas, tendo apresentado confiabilidade de uso (Figura 1).

Os resultados foram submetidos à análise de variância com uso do aplicativo SISVAR (Ferreira, 2008), sendo feitos testes de médias nos casos de efeito dos tratamentos qualitativos (fontes de nitrogênio) na variável dependente $\left(\mathrm{NO}_{3}^{-}\right)$e análises de regressão para as variáveis independentes quantitativas (concentrações de $\mathrm{NO}_{3}{ }^{-}$da água de irrigação).

Tabela 1. Atributos químicos do solo da área experimental

\begin{tabular}{|c|c|c|c|c|c|c|c|c|c|c|c|}
\hline \multirow{2}{*}{$\begin{array}{l}\text { Profundidade } \\
(\mathrm{m})\end{array}$} & \multirow{2}{*}{$\begin{array}{c}\mathrm{pH} \text { em } \\
\text { água }\end{array}$} & \multirow{2}{*}{$\begin{array}{c}P \\
\mathrm{mg} \mathrm{dm^{-3 }}\end{array}$} & $\mathrm{K}$ & $\mathrm{Ca}$ & $\mathrm{Mg}$ & $\mathrm{Ca}+\mathrm{Mg}$ & Al & $\mathrm{Na}$ & $\mathrm{H}+\mathrm{Al}$ & CTC & V \\
\hline & & & \multicolumn{8}{|c|}{$\mathrm{cmol}_{\mathrm{c}} \mathrm{dm}^{-3}$} & $\%$ \\
\hline 0,30 & 6,54 & 28,33 & 0,24 & 2,70 & 1,24 & 3,94 & 0,0 & 0,21 & 1,28 & 5,68 & 77,04 \\
\hline 0,60 & 5,72 & 15,82 & 0,13 & 1,56 & 0,84 & 2,40 & 0,15 & 0,28 & 2,00 & 4,82 & 57,62 \\
\hline
\end{tabular}




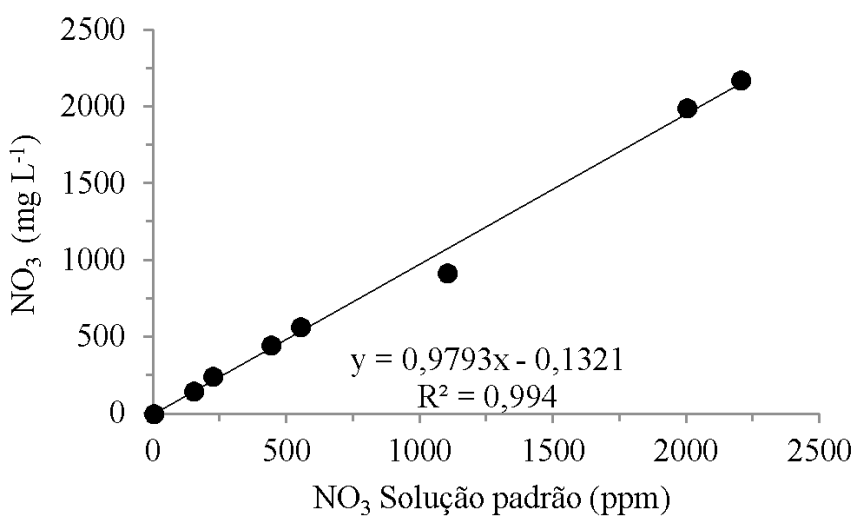

Figura 1. Curva de Calibração do aparelho Card horiba

\section{Resultados e Discussão}

A análise de variância detectou efeito apenas da fonte de nitrogênio e do tempo decorrido do plantio na concentração de nitrato na solução do solo. O nitrato de potássio ocasionou maior concentração média de nitrato na solução do solo considerando-se as profundidades 0,30 e 0,60 $\mathrm{m}$ em relação à ureia (Tabelas 2). Este resultado é justificado pelo fato de o ion nitrato $\left(\mathrm{NO}_{3}\right)$ de carga negativa ser diretamente liberado na solução do solo assim que o nitrato de potássio dissolvido na água de irrigação entra no meio poroso, não sendo adsorvido pelas micelas, o que não ocorre no caso da ureia, que precisa passar por processos de hidrólise que resulta em ions de carga positiva (amônio) e que pode ser retido nas micelas e nitrificação para resultar no íon nitrato (Alves et al., 2010).

As concentrações médias de nitrato da solução do solo nas profundidades de 0,30 e 0,60 m aumentaram desde o início do ciclo da cultura (janeiro de 2008) até dezembro de 2008, indicando que tanto a fonte ureia como o nitrato de potássio, independente da concentração $\left(2,7\right.$ a $\left.7,2 \mathrm{~g} \mathrm{~L}^{-1}\right)$ usada na aplicação do fertilizante numa frequência semanal, promoveram acúmulo do nitrato na zona radicular ao longo do tempo, sendo que a lixiviação ocorreu em baixa intensidade uma vez que não houve efeito da profundidade na concentração do nitrato na solução do solo.

As variações dos valores de nitrato observados sob as condições avaliadas em termos de concentração de ureia e de nitrato de potássio da água de irrigação ficaram dentro das faixas de valores encontrados por Kelling et al. (1977), que observaram teores de nitrato entre 78,0 e 225,0 $\mathrm{mg} \mathrm{L}^{-1}$ em diferentes concentrações de nitrato de amônio aplicados ao solo. Essas faixas de valores também ficaram próximas da encontrada por

Tabela 2. Concentraçãon $\left(\mathrm{mg} \mathrm{L}^{-1}\right)$ de nitrato na solução do solo sob duas fontes de nitrogênio, em três épocas de amostragem nas profundidades 0,30 e 0,60 m do solo

\begin{tabular}{ccccccc}
\hline Profundidade & \multicolumn{2}{c}{ Fonte } & & \multicolumn{3}{c}{ Época amostragem } \\
\cline { 2 - 3 } \cline { 5 - 7 }$(\mathbf{m})$ & Ureia & $\mathbf{K N O}_{3}$ & & $\mathbf{0 2 / 2 0 0 8}$ & $\mathbf{0 7 / 2 0 0 8}$ & $\mathbf{1 2 / 2 0 0 8}$ \\
0,30 & $70,2 \mathrm{a}$ & $92,4 \mathrm{~b}$ & & $42,4 \mathrm{a}$ & $70,4 \mathrm{~b}$ & $130,9 \mathrm{C}$ \\
0,60 & $83,1 \mathrm{a}$ & $95,7 \mathrm{a}$ & & $41,6 \mathrm{a}$ & $105,4 \mathrm{~b}$ & $121,3 \mathrm{~b}$ \\
\hline
\end{tabular}

\#Médias seguidas de mesmas letras na linha não diferem entre si ao nível de 0,05 de probabilidade
Andrade Neto (2012), que em estudo de validação de modelos de estimativa de nitrato monitorou, durante 400 dias, níveis de $\mathrm{NO}_{3}$ - na solução do solo entre 50 e 200,0 $\mathrm{mg} \mathrm{L}^{-1}$ e ficaram dentro das faixas obtidas por Cometti et al. (2008), que obtiveram teores de nitrato na solução do solo entre 21,8 a $174 \mathrm{mg} \mathrm{L}^{-1}$.

$\mathrm{O}$ aumento da concentração do fertilizante nitrogenado da água na fertigação implicou em aumento da concentração do ín nitrato na solução do solo para as duas fontes de nitrogênio aplicadas. Este resultado foi concordante com os obtidos por Andrade Neto (2009) que verificou aumento na concentração de nitrato no solo com aumento da concentração de ureia e de nitrato de cálcio na água de irrigação em solo de características semelhantes.

Teixeira et al. (2007) observaram, estudando os efeitos da fertigação com $\mathrm{N}$ e K sob os atributos químicos de um Argissolo Vermelho-Amarelo eutrófico, que a aplicação de nitrogênio no forma de nitrato de amônio via fertigação aumentou a acidez do solo em níveis proporcionais com o aumento das doses de $\mathrm{N}\left(100 \mathrm{~kg} \mathrm{ano}^{-1}\right)$, principalmente até $0,20 \mathrm{~m}$ de profundidade constatando uma redução de aproximadamente 0,08 unidade de $\mathrm{pH}$ no primeiro ciclo de cultivo e de 0,15 unidade no segundo ciclo.

A ureia resultou em maior taxa de crescimento da concentração do nitrato na solução do solo em relação ao nitrato de potássio na profundidade de $0,30 \mathrm{~m}$ (Figura $2 \mathrm{~A} \mathrm{e} \mathrm{B}$ ), embora ambas as fontes tenham tido uma taxa positiva de aumento; este resultado indica que a ureia, apesar dos processos que precisa passar antes de resultar em nitrato no solo, ou seja, hidrólises e nitrificação chegou a superar o nitrato em termos de taxa de aumento da concentração do nitrato na solução do solo.

$\mathrm{Na}$ profundidade de $0,60 \mathrm{~m}$ a taxa de acúmulo de nitrato em função do aumento da concentração do fertilizante na água de irrigação é maior sob aplicação de nitrato de potássio comparada à aplicação da ureia, isto é, é positiva para a fonte nitrato de potássio e negativa para a ureia, como consequência do que ocorre a $0,30 \mathrm{~m}$; no caso da aplicação de ureia (Figura $2 \mathrm{C}$, em virtude da retenção do amônio pelas micelas na camada superficial, menores quantidades de nitrato são obtidas pela nitrificação que por gradiente de potencial gravitacional e gradiente de concentração chegam por fluxo de massa a $0,60 \mathrm{~m}$. A quantidade de íons de nitrato que chega a 0,60 m é maior para a aplicação de nitrato de potássio, onde o íon nitrato por ter carga negativa não sofre adsorção pelas micelas descendo por fluxo de massa se não for absorvido pelas raízes ocasionando maior taxa de elevação da concentração em função do aumento da concentração do fertilizante na água de irrigação (Figura 2D).

A concentração de nitrato na solução do solo variou com o tempo desde o início do experimento e com o ciclo da cultura, apresentando comportamento diferenciado conforme a fonte de nitrogênio utilizada. Apesar de ambas as fontes resultarem em elevação da concentração com o tempo, o uso da ureia mostrou diferença entre os valores da concentração na profundidade 0,30 m nos meses de janeiro/2008 e julho/2008, 

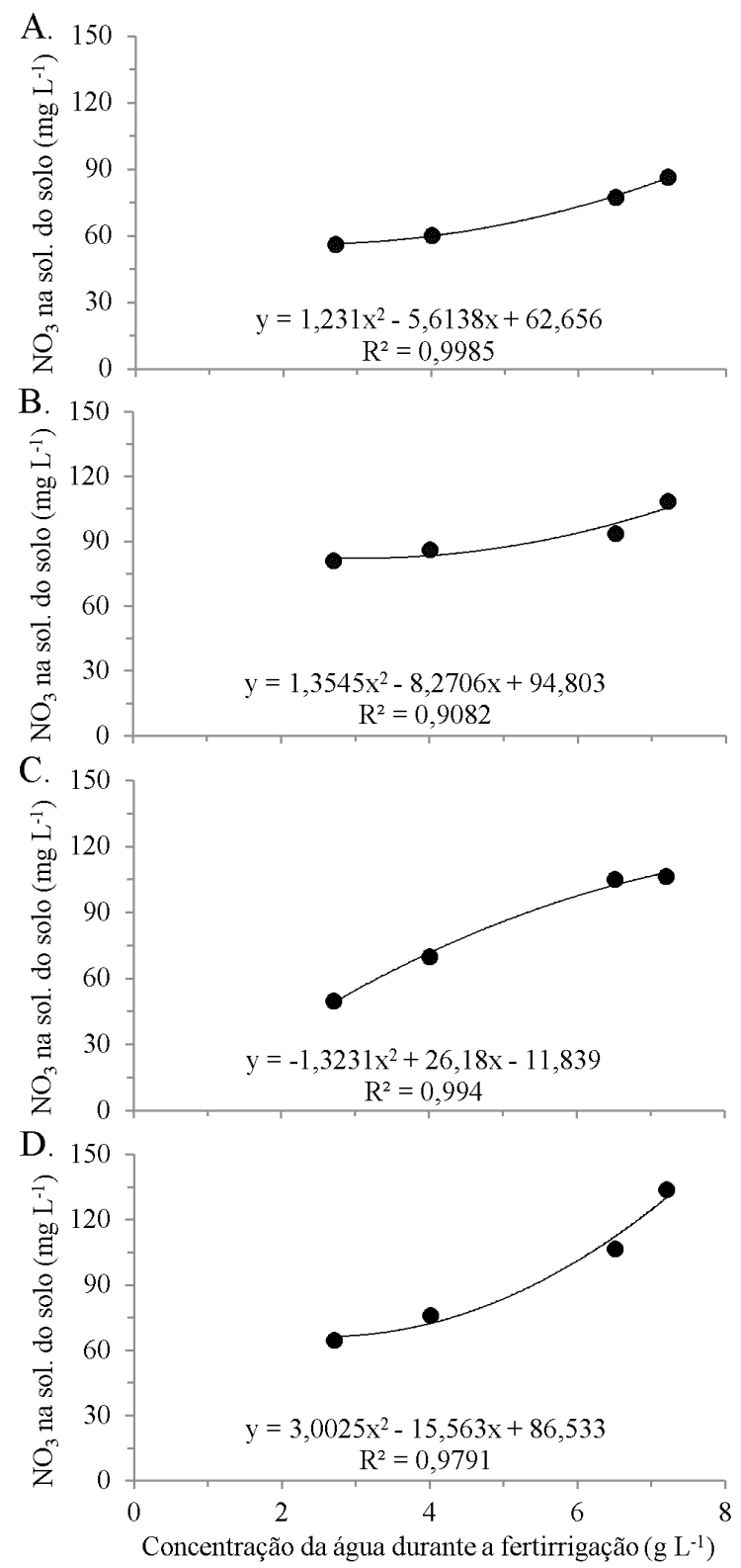

Figura 2. Concentração do íon nitrato em função da concentração da ureia na água de irrigação a 0,30 m de profundidade do solo $(\mathrm{A})$, do nitrato de potássio a $0,30 m$ (B) e em função da concentração de ureia a $0,60 \mathrm{~m}$ de profundidade do solo $(\mathrm{C})$ e do nitrato de potássio a $0,60 \mathrm{~m}(\mathrm{D})$

sem, entretanto, haver diferença entre julho e dezembro de 2008 (Tabela 3, Figura 3). O uso do nitrato de potássio como fonte de nitrogênio mostrou diferença entre as concentrações na mesma profundidade entre os três meses amostrados com elevação diferenciada entre os meses (Tabela 3).

O maior incremento da concentração do nitrato na solução do solo pela aplicação da ureia ocorreu de janeiro a julho devido à fertigação semanal em que de janeiro a julho foram aplicados $64 \%$ do total previsto no ano e nos meses restantes foram aplicados $36 \%$ do total previsto. O maior incremento da concentração do nitrato ocorreu entre julho e dezembro, o que reflete a maior mobilidade do nitrato no solo com maior acúmulo na profundidade considerada.
Tabela 3. Médias das concentrações de nitrato na solução do solo $\left(\mathrm{mg} \mathrm{L}^{-1}\right)$ nas profundidades $0,30 \mathrm{e}$ $0,60 \mathrm{~m}$ sob aplicação das fontes de nitrogênio ureia e nitrato de potássio

\begin{tabular}{cccc}
\hline Profundidade & Época & \multicolumn{2}{c}{ Fonte de nitrogênio } \\
\cline { 3 - 4 }$(\mathbf{m})$ & Janeiro & $39,08 \mathrm{a}$ & \multicolumn{1}{c}{$\mathbf{K N O}_{3}$} \\
& Julho & $77,25 \mathrm{~b}$ & $63,62 \mathrm{~b}$ \\
0,30 & Dezembro & $94,12 \mathrm{~b}$ & $167,79 \mathrm{C}$ \\
& Janeiro & $50,00 \mathrm{a}$ & $33,12 \mathrm{a}$ \\
& Julho & $88,16 \mathrm{~b}$ & $122,58 \mathrm{~b}$ \\
0,60 & Dezembro & $111,12 \mathrm{~b}$ & $131,60 \mathrm{~b}$ \\
\hline
\end{tabular}

Médias seguidas de mesmas letras na coluna não diferem entre si a nível de 0,05 de probabilidade
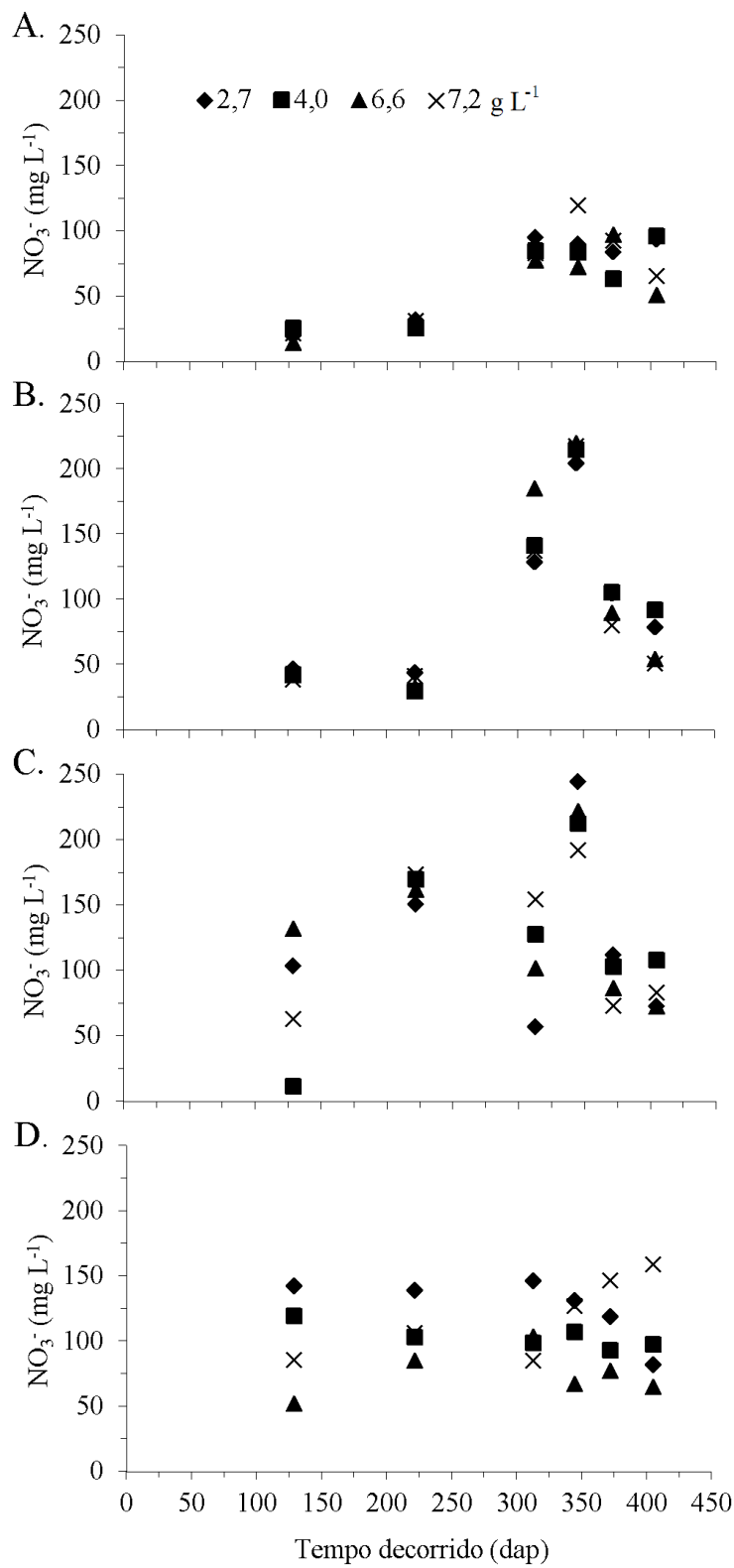

Figura 3. Evolução da concentração do íon nitrato em função da concentração da ureia na água de irrigação a $0,30 \mathrm{~m}$ de profundidade do solo (A), do nitrato de potássio a $0,30 \mathrm{~m}$ (B) e em função da concentração de ureia a $0,60 \mathrm{~m}$ de profundidade do solo (C) e do nitrato de potássio a $0,60 \mathrm{~m}(\mathrm{D})$ 
Os incrementos da concentração de nitrato na solução do solo com o tempo na profundidade $0,60 \mathrm{~m}$ (Tabela 3, Figura 3) seguiram, no caso da ureia, o mesmo comportamento observado a $0,30 \mathrm{~m}$, mas com comportamento diferente para a aplicação do nitrato de potássio, com maior incremento entre janeiro e julho de 2008, sendo que entre julho e dezembro não houve diferença entre as concentrações do nitrato o que pode ser explicado pelas maiores percentagens mensal do fertilizante aplicado entre janeiro e julho de 2008.

A concentração de nitrato no extrato de saturação como média no perfil 0,30 - 0,60 m não foi influenciada pela fonte de nitrogênio conforme análise de variância (Tabela 4) indicando que a concentração média correspondente ao período de janeiro e dezembro de 2008 não diferiu entre as profundidades de 0,30 e $0,60 \mathrm{~m}$.

Tabela 4. Concentração média de nitrato no extrato de saturação $\left(\mathrm{mg} \mathrm{L}^{-1}\right)$ nas profundidades 0,30 e 0,60 $\mathrm{m}$ sob aplicação de duas fontes de nitrogênio, em três épocas decorridas do início do experimento, em duas profundidades

\begin{tabular}{ccccccc}
\hline Prof. & \multicolumn{2}{c}{ Fonte de nitrogênio } & & \multicolumn{3}{c}{ Tempo do início do experimento } \\
\cline { 2 - 3 } \cline { 5 - 7 }$(\mathbf{m})$ & Ureia & KNO $_{3}$ & & Janeiro & Julho & Dezembro \\
0,30 & 51,22 & 54,06 & & 41,61 & 42,18 & 73,80 \\
0,60 & 46,28 & 50,43 & & 34,14 & 35,50 & 75,41 \\
\hline
\end{tabular}

A análise de regressão dos valores de concentração do nitrato no extrato de saturação do solo em função da concentração da água de irrigação teve comportamento semelhante ao da solução do solo. Na profundidade $0,30 \mathrm{~m}$ a concentração de nitrato no extrato de saturação em relação à concentração de ureia ou nitrato de potássio na água de irrigação seguiu uma função polinomial do segundo grau (Figura 4A e B), numa taxa de aumento constante sendo que foram verificadas maiores taxas de aumento da concentração de nitrato no extrato de saturação para a aplicação de ureia até a concentração de $4,5 \mathrm{~g} \mathrm{~L}^{-1}$, acima da qual os maiores valores foram encontrados para a aplicação de nitrato de potássio. Na profundidade de $0,60 \mathrm{~m}$, a concentração de nitrato se comportou seguindo uma função polinomial do segundo grau em relação à ureia e ao nitrato de potássio (Figuras $4 \mathrm{C}$ e D), mas com taxa de aumento constante e decrescente sendo que a ureia proporcionou maiores taxas de crescimento da concentração de nitrato no extrato de saturação em relação à aplicação do nitrato de potássio. Em ambas as profundidades houve aumento da concentração de nitrato no extrato de saturação com a concentração da fonte nitrogenada (ureia ou nitrato de potássio); entretanto, a taxa de elevação da concentração de nitrato foi crescente a 0,30 $\mathrm{m}$ e decrescente a $0,60 \mathrm{~m}$, indicando baixa movimentação em profundidade do nitrato com maior acúmulo a $0,30 \mathrm{~m}$.

A concentração de nitrato no extrato de saturação não apresentou variação entre o início do experimento (janeiro) e julho de 2008, com elevação entre julho e dezembro de 2008 em ambas as profundidades (Figura 5), ou seja, o efeito da aplicação das fontes de nitrogênio pela fertigação em diferentes concentrações só ocorreu entre julho e dezembro. O extrato de saturação representa
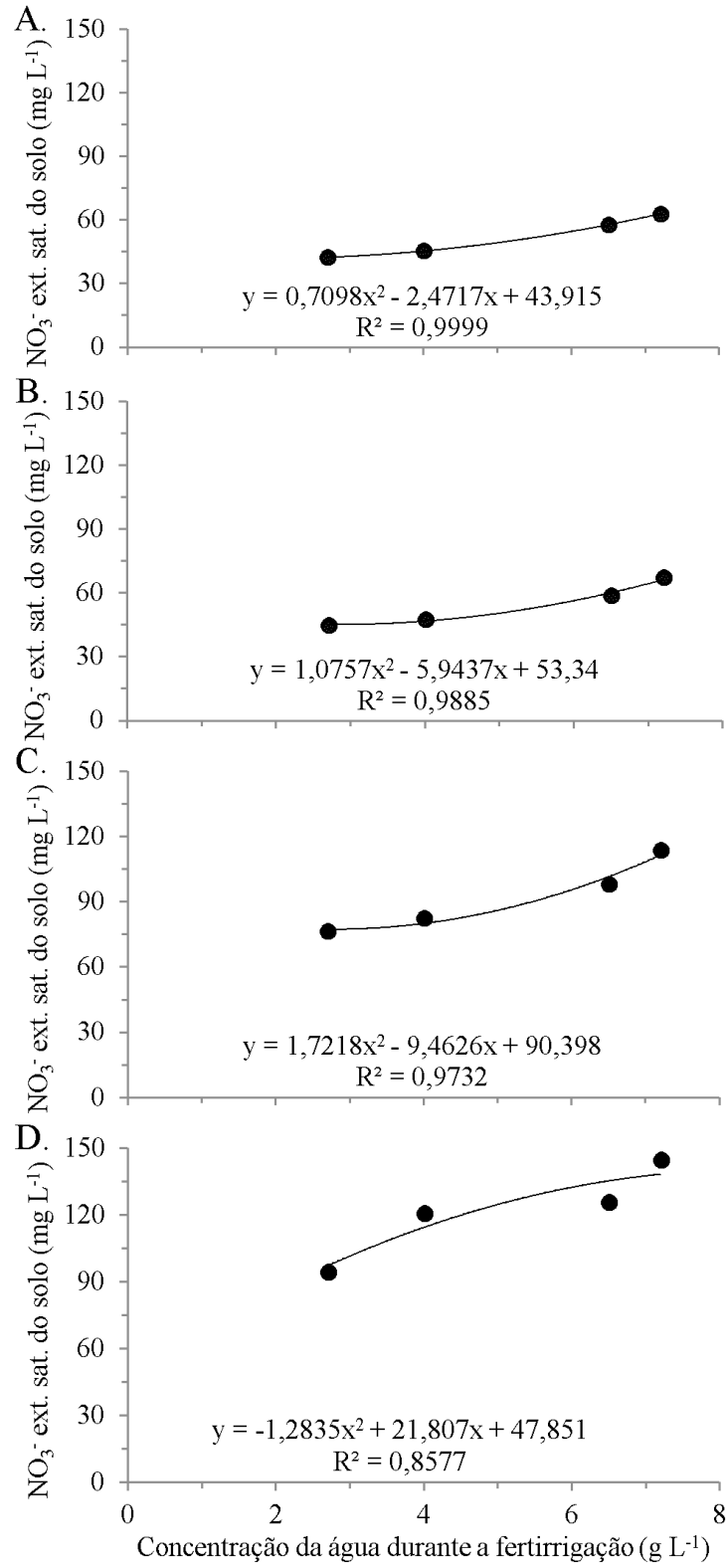

Figura 4. Concentração do íon nitrato no extrato de saturação em função da concentração da ureia na água de irrigação a $0,30 \mathrm{~m}$ de profundidade do solo (A), do nitrato de potássio a $0,30 \mathrm{~m}$ (B) e em função da concentração de da ureia na água de irrigação a 0,60 $\mathrm{m}$ de profundidade do solo $(\mathrm{C})$ e da concentração do nitrato de potássio na água de irrigação a 0,60 m (D)

uma condição de máxima diluição em virtude da saturação do solo tornando os valores das concentrações de nitrato inferiores aos da concentração da solução do solo.

Os maiores valores observados em dezembro se devem ao aumento da concentração do nitrato na solução do solo entre julho e dezembro o que, somado à concentração existente na dupla camada difusa, resultou no aumento da concentração do nitrato no extrato de saturação em dezembro de 2008 variando de $60 \%$ no caso da ureia a $0,30 \mathrm{~m}, 92 \%$ no caso do nitrato de potássio, $100 \%$ no caso da ureia a $0,60 \mathrm{~m}$ e $169 \%$ no caso do nitrato de potássio a $0,60 \mathrm{~m}$ (Tabela 5). A maior variação 

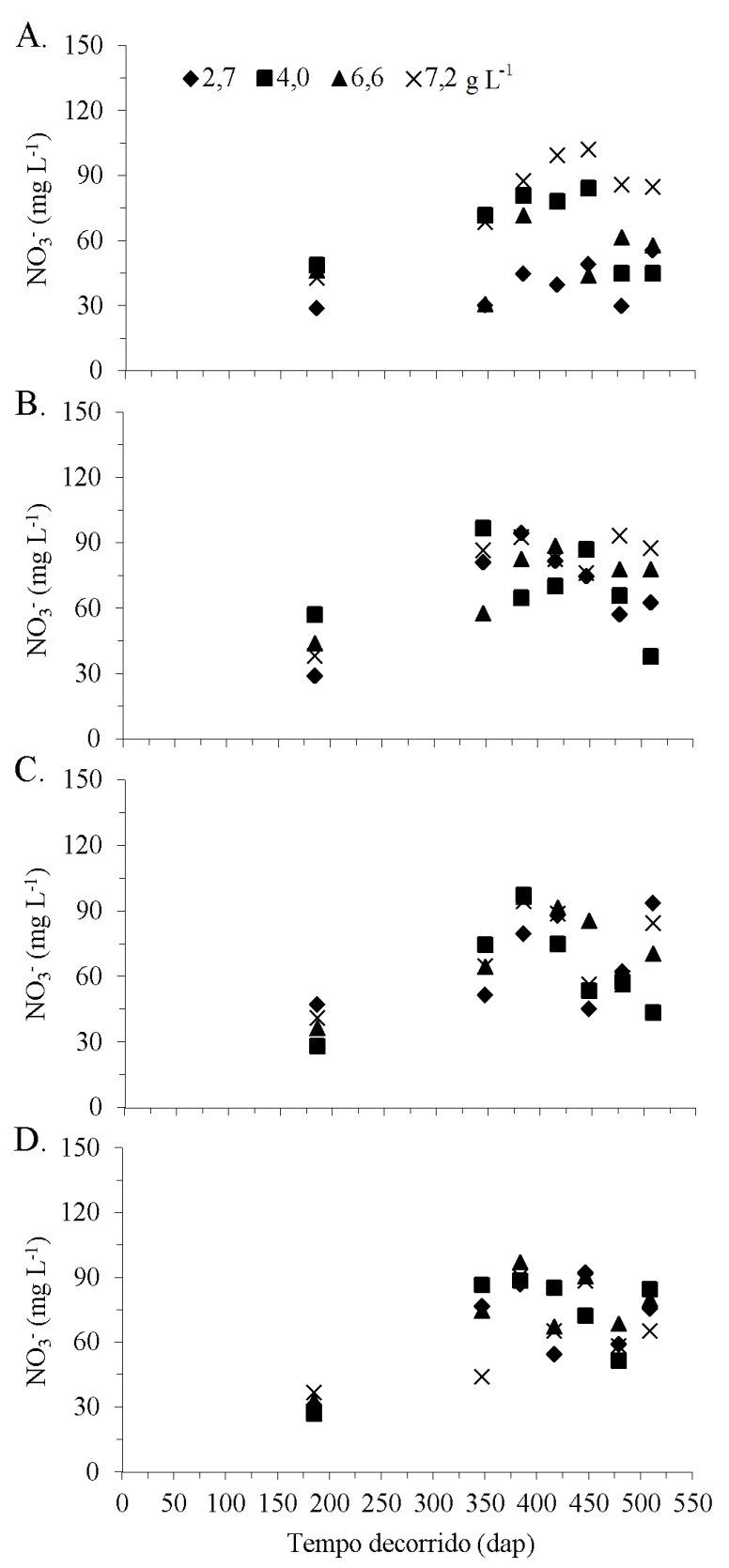

Figura 5. Evolução da concentração do íon nitrato em função da concentração da ureia na água de irrigação a $0,30 \mathrm{~m}$ de profundidade do solo (A), do nitrato de potássio a $0,30 \mathrm{~m}$ (B) e em função da concentração de ureia a 0,60 $\mathrm{m}$ de profundidade do solo (C) e do nitrato de potássio a $0,60 \mathrm{~m}(\mathrm{D})$

Tabela 5. Médias das concentrações de nitrato na solução do solo $\left(\mathrm{g} \mathrm{L}^{-1}\right)$ nas profundidades 0,30 e 0,60 $\mathrm{m}$ com aplicação das fontes de nitrogênio ureia e nitrato de potássio

\begin{tabular}{clcc}
\hline Profundidade & \multirow{2}{*}{ Período } & \multicolumn{2}{c}{ Fonte de nitrogênio } \\
\cline { 3 - 4 } & & Ureia & KNO $_{3}$ \\
& Janeiro & $41,95 \mathrm{a}$ & $42,41 \mathrm{a}$ \\
0,30 & Julho & $41,91 \mathrm{a}$ & $41,36 \mathrm{a}$ \\
& Dezembro & $67,14 \mathrm{~b}$ & $81,58 \mathrm{~b}$ \\
& Janeiro & $36,75 \mathrm{a}$ & $32,41 \mathrm{a}$ \\
0,60 & Julho & $38,59 \mathrm{a}$ & $32,54 \mathrm{a}$ \\
& Dezembro & $64,50 \mathrm{~b}$ & $86,33 \mathrm{~b}$ \\
\hline
\end{tabular}

observada pela aplicação de nitrato de potássio é devida ao fato da maior variação da solução do solo ter ocorrido para o nitrato de potássio, que se justifica pela maior mobilidade ou dinâmica do nitrato com que é aplicado, no caso pelo nitrato de potássio. O nitrato resultante da aplicação da ureia leva mais tempo para entrar em solução em razão das reações químicas que ocorrem desde a infiltração da ureia no solo até a nitrificação do amônio.

As elevações da concentração de uréia ou de nitrato de potássio na solução de injeção ocasionam níveis de nitrato na solução do solo que tendem a se elevar com o tempo. Os valores observados da concentração de nitrato foram considerados dentro das faixas normais não causadores, portanto, de impactos negativos no solo para as plantas ou para contribuir para contaminação dos lençois freáticos o que, embora não tenha sido avaliado, a não diferença entre as concentrações na profundidade 0-0,60 m permite tal afirmação.

\section{Conclusões}

1. O aumento da concentração do fertilizante nitrogenado da água na fertigação implicou em aumento da concentração do íon nitrato na solução do solo e no extrato de saturação para as duas fontes de nitrogênio aplicadas.

2. A taxa de acúmulo de nitrato na solução do solo a $0,30 \mathrm{~m}$ de profundidade foi maior para a aplicação de ureia enquanto na profundidade $0,60 \mathrm{~m}$ foi maior para a aplicação de nitrato de potássio.

3. A taxa de elevação da concentração de nitrato no extrato de saturação em relação à concentração do fertilizante nitrogenado na água de irrigação foi crescente a $0,30 \mathrm{~m} \mathrm{e}$ decrescente a $0,60 \mathrm{~m}$.

4. A concentração média de nitrato da solução do solo nas camadas 0 - 0,30 e 0,30 - 0,60 m aumentou desde o início do ciclo da cultura (janeiro de 2008) até dezembro de 2008.

\section{Literatura Citada}

Alves, M. S.; Coelho, E. F.; Paz, V. P. S.; Andrade Neto, T. M. Crescimento e produtividade da bananeira cv. Grande Naine sob diferentes combinações de nitrato de cálcio e ureia. Revista Ceres, v.57, p.125-131, 2010.

Andrade, E. M. de; Aquino, D. N. de; Crisóstomo, L. de A.; Rodrigues, J. de O.; Lopes, F. B. Impacto da lixiviação de nitrato e cloreto no lençol freático sob condições de cultivo irrigado. Ciência Rural, v.39, p.88-95, 2009.

Andrade Neto, T. M. Monitoramento de íons na solução e no extrato de saturação do solo sob aplicação de diferentes concentrações de sais fertilizantes na água de irrigação em bananeira da terra. Cruz das Almas: UFRB, 2009. 78p. Dissertação Mestrado

Andrade Neto, T. M. Monitoramento de íons na solução do solo e no extrato de saturação em fertigação. Cruz das Almas: UFRB, 2012. 78p. Tese Doutorado

Borges, A. L.; Silva, T. O. da; Caldas, R. C.; Almeida, I. E. de. Adubação nitrogenada para bananeira-'Terra' (Musa sp. AAB, subgrupo Terra). Revista Brasileira de Fruticultura, v.24, p.189-193, 2002. 
Coelho, E. F; Donato, S. L. R.; Oliveira, P. M.; Cruz, A. J. S.. Relações hídricas II: Evapotranspiração e coeficiente de cultura. In: Coelho, E. F. (org.). Irrigação da bananeira. 1.ed. Cruz das Almas: Embrapa Mandioca e Fruticultura, v.1, p.87-117, 2012,

Coelho, E. F.; Ledo, C. A. da S.; Silva, S. de O. Produtividade da bananeira 'Prata-Anã' e 'Grande Naine' no terceiro ciclo sob irrigação por microaspersão em tabuleiros costeiros da Bahia. Revista Brasileira de Fruticultura, v.28, p.435-438, 2006.

Cometti, N. N.; Matias, G. C. S.; Zonta, E.; Mary, W.; Fernandes, M. S.. Efeito da concentração da solução nutritiva no crescimento da alface em cultivo hidropônico-sistema NFT. Horticultura Brasileira, v.26, p.262-267, 2008.

Donagemma, G. K.; Ruiz, H. A.; Alvarez, V. H.; Ferreira, P. A.; Cantarutti, R. B.; Silva, A. T. da; Figueiredo, G. C. Distribuição do amônio, nitrato, potássio e fósforo em colunas de latossolos fertirrigadas. Revista Brasileira de Ciência do Solo, v.32, p.2493-2504, 2008.

EMBRAPA - Empresa Brasileira de Pesquisa Agropecuária. Centro Nacional de Pesquisa de Solos. Manual de métodos de análise de solo. 2. ed. rev. atual. Rio de Janeiro, Embrapa CNPS, 1997. 212p. Documentos, 1
Ferreira, D. F. SISVAR: Um programa para análise e ensino de estatística. Revista Symposium, v.6, p.36-41, 2008.

Kelling, K. A.; Walsh, L. M.; Keeney, D. R.; Ryan, J. A.; Peterson, A. E. A field study of the agricultural use of sewage sludge: II. Effect on soil N and P. Journal of Environmental Quality, v.6, p.345-352, 1977.

Santana, G. S.; Coelho, E. F.; Silva, T. M.; Ramos, M. M. Relação entre potássio na solução do solo, umidade e condutividade elétrica aparente do solo. Revista Brasileira de Engenharia Agrícola e Ambiental. v.11, p.142-151, 2007.

Silva, J. T. A. da; Borges, A. L. Solo, nutrição mineral e adubação da bananeira. Informe Agropecuário, v.29, p.25-37, 2008.

Souza, E. A.; Coelho, E. F.; Paz, V. P. S.; Coelho Filho, M. A. Crescimento e produtividade do mamoeiro fertirrigado com fósforo por gotejamento superficial e subsuperficial. Revista Brasileira de Fruticultura, v.27, p.495-499, 2005.

Teixeira, L. A. J.; Natale, W.; Bettiol Neto, J. E.; Martins, A. L. M. Nitrogênio e potássio em bananeira via fertigação e adubação convencional - atributos químicos do solo. Revista Brasileira de Fruticultura, v.29, p.143-152, 2007.

Teixeira, L. A. J.; Quaggio, J. A.; Mellis, E. V. Ganhos de eficiência fertilizante em bananeira sob irrigação e fertigação. Revista Brasileira de Fruticultura, v.33, p.272-278, 2011. 